\title{
The Effect of Labour Turnover Costs on Average Labour Demand When Recessions Are More Persistent than Booms
}

\author{
Pilar Díaz-Vázquez and Luis E. Arjona-Béjar \\ Departamento de Fundamentos del Análisis Económico, Facultad de Ciencias Económicas y Empresariales, Universidad de Santiago \\ de Compostela, Avenida do Burgo S/N, A Coruña, 15784 Santiago de Compostela, Spain \\ Correspondence should be addressed to Pilar Díaz-Vázquez; p.diaz@usc.es
}

Received 10 December 2012; Accepted 26 December 2012

Academic Editors: T. Kuosmanen, J. M. Labeaga, and A. Watts

Copyright (C 2013 P. Díaz-Vázquez and L. E. Arjona-Béjar. This is an open access article distributed under the Creative Commons Attribution License, which permits unrestricted use, distribution, and reproduction in any medium, provided the original work is properly cited.

\begin{abstract}
This paper examines how labour turnover costs affect average labour demand when troughs are more persistent than booms. We show that the effect of firing costs on average labour demand is more expansionary (or less contractionary): the greater is the difference between the persistence of troughs and the persistence of booms, and the more prolonged are the macroeconomic shocks. This analysis may shed some light on the expected effect of a reduction of firing costs when an economy is suffering more prolonged recessions (relative to booms): average labour demand will be lower.
\end{abstract}

\section{Introduction}

Politicians and journalists often attribute the high unemployment in many European countries to their stringent job security legislation, and particularly to their state-mandated firing costs. However, the theoretical literature on the longrun effects of firing costs on employment has generated mixed results (There is also no agreement in the empirical literature. See OECD [1], Layard et al. [2], Lazear [3], Bertola [4], Hopenhayn and Rogerson [5], Nickell [6], Heckman and Pages [7].). Bentolila and Bertola [8] and Bertola [9] have argued that firing costs tend to raise (rather than reduce) the average level of employment since they discourage firing more than hiring in any given firm. Other contributions show factors that pull in the opposite direction: Bentolila and SaintPaul [10] indicate that when firms face heterogeneous productivity shocks, a rise in firing costs reduces the number of firms engaged in firing. Hopenhayn and Rogerson [5] consider that the increase in firing costs reduces the entry of firms (in an industry equilibrium with firm entry and exit) and thus labour demand falls. Díaz-Vázquez et al. [11] show that when there is on-the-job learning, an increase in firing costs may reduce average employment over the cycle. This paper and Díaz-Vázquez and Snower [12-14] also show that the wage effects of firing costs may reduce average employment (as shown in the literature, firing costs give power to insiders in the wage negotiation (see Lindbeck and Snower, [15])). Ljungqvist and Sargent [16] argue that the existence of firing costs can help explain the high European unemployment of recent decades.

However, this literature has not investigated how the average employment effect of firing costs depends on the asymmetry in the persistence of macroeconomic booms and troughs (in Bentolila and Bertola [8], the shocks are permanent (namely, they are assumed to follow a random walk process), whereas in Bentolila and Saint-Paul [10] they are temporary (namely, they are white noise). Bertola [4] and Díaz-Vázquez and Snower [12] analyze shocks whose degree of persistence lies between these two extremes (with the degree of persistence determined by the transition probabilities in a Markov process). In all of these models, macroeconomic upturns and downturns are assumed to be equally likely. Nunziata [17] analyzes the effect of firing costs on the dynamics of employment over the cycle, but he does not study the average effect.). This asymmetry is important since booms and troughs have very different implications for the influence of firing costs on employment. Chen et al. [18] indicate that when the level of macroeconomic activity is expected to drop (or growth is low), a rise in firing costs affects mainly (and adversely) the hiring decision, whereas firing costs can 
raise employment during periods of high growth and positive shocks. However, they do not analyse the effect of firing costs on long-run employment neither they consider the effect of firing costs via the negotiated wage.

The contribution of this paper is to present a model in which troughs are more persistent than booms and turnover costs also affect employment via the negotiated wage. In this context, we examine how the effect of turnover costs on labour demand depends on the persistence of macroeconomic fluctuations (our approach is different from the literature that studies the effect of firing costs on business cycle fluctuations (see Veracierto [19] and Zanetti [20]). We focus on how average labour demand responds to turnover costs when the macroeconomic conditions change). Turnover costs have an ambiguous effect on average employment: on the one hand, (i) turnover costs increase employment because they discourage the firing of workers in recessions. When the firm encounters a recession, it faces the possibility of firing workers and paying the firing cost in the current period. This current payment discourages firing and increases employment. Additionally, if economic conditions improve, firms will have to pay the hiring cost. On the other hand, (ii) turnover costs diminish employment because they discourage hiring and augment the wage in booms. When economic conditions improve and the firm considers the possibility of hiring new workers, not only the hiring cost but also the expectation of paying the firing cost in the future discourages hiring. Additionally, in booms workers may obtain higher wages if they are protected by job security provisions. The reason is that firing costs worsen the firm's fall-back position in the negotiations, which increases the wage. The cost of hiring also increases the wage in booms. The influence of turnover costs on the wage depends on the bargaining power of the workers. For this reason, the greater the strength of employees in the wage bargaining process, the more contractionary is the effect of turnover costs on average employment. Note that firing costs only increase the wage in booms, since in troughs the rise in the firing cost worsens the firm's fall-back position by just as much as it reduces the marginal product of labour.

It is clear that when the persistence of troughs is greater than the persistence of booms, the economy will be more frequently in recessions than in booms. In this case, the aspect (i) becomes more important than (ii), and it is more likely that firing costs increase average employment. Any factor that increases the frequency of troughs will have this consequence. Thus, the more persistent are troughs relative to booms, the more expansionary or the less contractionary is the effect of firing cost on average employment.

In this context, we also demonstrate that when troughs are more persistent than booms, a proportional increase in the persistence of both booms and troughs gives turnover costs a more expansionary or a less contractionary influence on average employment. We can show that the frequency of troughs relative to booms may increase due to a proportional increase in the persistence of both booms and troughs: it is clear that if the economy is in troughs a greater number of periods, a proportional increase in the duration of both booms and recessions will increase the frequency of recessions and reduce the frequency of booms.
In this context of asymmetric fluctuations, we also examine how the effect of turnover costs on average employment depends on the characteristics of the firms' production functions (in this respect, we extend the results of Bertola [9] to a stochastic framework). In this context we show that the results above may hold for different production functions.

The paper is organized as follows. Section 2 presents the model. Section 3 analyzes the influence of firing costs on employment in the short run whereas Section 4 analyzes the influence of firing costs on employment in the long run. Section 5 presents the conclusions.

\section{The Model}

Consider a firm that produces a homogeneous output by means of a homogeneous labour input. In time period $\tau$ its revenue function is $R\left(Z_{\tau}, L_{\tau}\right)$, where $Z_{\tau}$ is a random variable representing business conditions, and $L_{\tau}$ is the firm's employment (we assume perfect competition in the product market, so that the firm is a price taker.). The evolution of business conditions $Z_{\tau}$ is given by a two-state Markov chain: there is a "good state" when $Z_{\tau}=Z^{G}$ and a "bad state" when $Z_{\tau}=Z^{B}$, where $Z^{G}>Z^{B}$. The probability of remaining in the good state is $P^{G}$ and the probability of remaining in the bad state is $P^{B}$, so that the matrix of stationary transition probabilities is

$$
\left(\begin{array}{cc}
P^{G} & 1-P^{G} \\
1-P^{B} & P^{B}
\end{array}\right) .
$$

In this context, the persistence of a good state (i.e., the persistence of a boom) and the persistence of a bad state (i.e. the persistence of a trough) are measured by the probabilities $P^{G}$ and $P^{B}$. When the firm makes its employment decision, it has complete information about current business conditions, $Z^{i}$. Regarding the future, the firm has rational expectations of $Z_{\tau}$, knowing the above Markov matrix but not the realized value of $Z_{\tau}$.

When a new member of the workforce is hired, the firm pays a hiring cost $H$, and, when an incumbent worker is fired, the firm bears a firing cost $F$, where $H$ and $F$ are positive constants. For simplicity, we assume that the positions of employees in the firm are protected by the firing cost $F$ and that all workers have the same productivity, that is, the same marginal product for any given level of employment.

Each worker receives a real wage $W_{\tau}$ per period $\tau$. The wage $W_{\tau}$ is the outcome of an individualistic Nash bargain between the firm and each worker, where the employment of all other workers is taken as given (assuming a sufficiently large workforce, the firm's total employment may be taken as given in the wage setting process). Thus each employee is perceived as the marginal worker in the bargaining process, implying that the firm's expected profit under agreement is the worker's marginal profit $\left(M_{\tau}^{i}-W_{\tau}^{i}-h_{\tau}\right)$, where $M_{\tau}^{i}$ is the present value of the marginal employee's expected profits, excluding the current labour cost (to be defined formally below); $W_{\tau}^{i}$ is the employee's current wage; and $h_{\tau}=$ $H$ when the firm is hiring and $h_{\tau}=0$ when it is not hiring. 
(The firing cost is not relevant here since the marginal worker, by definition, is not fired.)

Under disagreement, employees are assumed to produce no output and undertake industrial action in order to impose a cost on the firm. We assume that workers can manipulate the level of industrial action without any cost to themselves, and thus they set it as high as possible. However, if the cost of the industrial action is higher than the cost of dismissing the worker, it will be optimal for the firm to dismiss the worker. Accordingly, since workers wish to retain their positions in the firm, they will set the level of the industrial action so that the firm is made indifferent between retaining or dismissing the workers. The firm's cost of dismissing a worker is $F+k+$ $h_{\tau}$, where $F$ is the firing cost and $k(k>0)$ is a further loss that does not depend on the magnitude of the labour turnover costs (such as the loss of customer good will). Consequently, the worker will set the level of the industrial action such that the firm's marginal profit under disagreement is $-\left(F+k+h_{\tau}\right)$.

The worker's income surplus in the wage bargain is $W_{t}^{i}-$ $W^{0}$, where $W_{\tau}^{i}$ is the wage under agreement in period $\tau$ and $W^{0}$ is the worker's fall-back position. Observe that the worker's future expected wages do not enter the worker's income surplus. The reason is that since the worker is not dismissed, the breakdown in the negotiations has no effect on the worker's future expected wages. (Since the expected future stream of wages is identical under agreement and under disagreement, it does not change the worker's strategic position in the wage negotiation.)

Thus the Nash bargaining problem is

$$
\underset{W_{\tau}^{i}}{\operatorname{Maximize}} \Omega=\left(W_{\tau}^{i}-W^{0}\right)^{\mu}\left(M_{\tau}^{i}-W_{\tau}^{i}-h_{\tau}\right)^{1-\mu},
$$

and the solution is the negotiated wage:

$$
W_{\tau}^{i}=(1-\mu) W^{0}+\mu\left(M_{\tau}^{i}+F+k\right) .
$$

In other words, the negotiated wage is a weighted average of the employee's fall-back position and the firm's surplus (excluding the wage).

The firm's employment decision is given by the following profit maximization problem:

$$
\begin{aligned}
& \underset{L_{t}}{\operatorname{Maximize}} E \sum_{\tau=t}^{\infty} \delta^{\tau-1}\left\{R\left(Z_{\tau}, L_{\tau}\right)-W_{\tau} L_{\tau}\right. \\
& \left.-C_{\tau}\left(L_{\tau}-L_{\tau-1}\right)\right\} \text {, }
\end{aligned}
$$

where $\delta$ is the discount factor. The first term is the firm's real revenue. The second term is its wage cost, where the wage $W_{\tau}$ is given by (3). (Observe that $W_{\tau}^{i}$ depends on the marginal worker's expected profit (minus the current labor cost) $M_{\tau}^{i}$, which, in turn, depends on employment. Thus, when the firm makes its decision on employment, it can predict the wage bargaining response.) The third term is its labour turnover cost, where $C_{\tau}=H$ when $L_{\tau}-L_{\tau-1}>0$ and $C_{\tau}=-F$ when $L_{\tau}-L_{\tau-1}<0$.

For given values of the parameters, business conditions (represented by $Z^{G}$ and $Z^{B}$ ) determine the firm's decision on whether to hire or fire. To focus on nontrivial results, we assume that the values of $Z^{G}$ and $Z^{B}$ are such that there are three scenarios.

(A1) The firing scenario: when economic conditions deteriorate, the firm finds it optimal to fire some of its insiders.

(A2) The hiring scenario: when economic conditions improve, it is optimal to hire new workers.

(A3) The retention scenario: when economic conditions do not change, any previous workforce is retained by the firm.

The firm's employment decision is the solution of the dynamic optimization problem (4). It can be shown that the associated marginal condition for employment is

$$
M_{t}^{i}-W_{t}^{i}-C_{t}=0 .
$$

In words, the optimal level of employment is set so that the discounted stream of the marginal employee's expected current and future profits is zero. Note that this equation is equivalent to the condition that the marginal worker's expected stream of revenue and wage cost is equal to the turnover cost (hiring cost $H$ in a good state and firing cost $-F$ in a bad state).

Let us now examine the form this marginal condition takes in the good and bad states. By the wage equation in (3) and the marginal employment condition in (5), the equilibrium wage in a good state is

$$
W_{t}^{G}=W^{0}+\frac{\mu}{1-\mu}(H+F+k)
$$

whereas in a bad state it is (this wage is unaffected by turnover costs, since $F$ reduces both the firm's fall-back position $(-F-$ $k$ ) and the marginal profitability of the worker $(-F)$ so that the firm's profit surplus is not changed)

$$
W_{t}^{B}=W^{0}+\frac{\mu}{1-\mu} k .
$$

As shown in the appendix, the expected marginal profit (excluding labour costs) in the good state is

$$
M_{t}^{G}=M R_{t}^{G}\left(Z^{G}, L_{t}^{G}\right)-\frac{\partial W_{t}^{G}}{\partial L_{t}^{G}} L_{t}^{G}+\delta\left[P^{G} H-\left(1-P^{G}\right) F\right]
$$

which may be interpreted as follows.

(i) The first term is the current marginal revenue.

(ii) The second term is the wage bargaining response to the employment decision: The employment of the marginal worker reduces the marginal profit and, consequently, reduces the negotiated wage. Observe that, by (3),

$$
\frac{\partial W_{t}^{G}}{\partial L_{t}^{G}}=\mu \frac{\partial M_{t}^{G}}{\partial L_{t}^{G}}=\frac{\mu}{1+\mu} \frac{\partial M R_{t}^{G}}{\partial L_{t}^{G}} .
$$


Thus any increase in employment reduces the bargained wage, which further raises employment. This "feedback effect" ensures that any change in employment is amplified through the bargained wage.

(iii) The third term of (8) is the workers' future profitability: with probability $P^{G}$ the economy remains in a good state in period $t+1$, in which, as in period $t$, the marginal worker's profitability equals the hiring cost $H$. With probability $\left(1-P^{G}\right)$ the economy falls into a bad state, in which the firm dismisses the marginal worker and pays the firing cost $F$.

Observe that, in (8), the firm's production technology affects labour demand both through the form of the marginal revenue function $\operatorname{MR}_{t}^{G}\left(Z^{G}, L_{t}^{G}\right)$ and through the feedback effect of (9). Thus it is convenient to define the "net marginal revenue" $(N M R)$ as the sum of the marginal revenue and the feedback effect:

$$
\operatorname{NMR}_{t}^{G}\left(Z^{G}, L_{t}^{G}\right)=M R_{t}^{G}\left(Z^{G}, L_{t}^{G}\right)-\frac{\mu}{1+\mu} \frac{\partial M R_{t}^{G}}{\partial L_{t}^{G}} L_{t}^{G}
$$

Substituting $M_{t}^{G}$ (8) and $W_{t}^{G}$ (6) into the marginal condition (5), we obtain the marginal condition for hiring (in a good state, i.e. a boom) (observe that this condition holds in any good state, since the firm is facing the same economic conditions as in hiring times. Thus, in the retention scenario this condition is satisfied although no new workers are hired):

$$
\begin{gathered}
\operatorname{NMR}_{t}^{G}\left(Z^{G}, L_{t}^{G}\right)-\left[W^{0}+\frac{\mu}{1-\mu}(F+H+k)\right] \\
+\delta\left[P^{G} H-\left(1-P^{G}\right) F\right]=H .
\end{gathered}
$$

Along the same lines it can be shown that the expected marginal profit (excluding the labour costs) in the bad state is

$$
\begin{aligned}
M_{t}^{B}= & M R_{t}^{B}\left(Z^{B}, L_{t}^{B}\right)-\frac{\partial W_{t}^{B}}{\partial L_{t}^{B}} L_{t}^{B} \\
& +\delta\left[-P^{B} F+\left(1-P^{B}\right) H\right]
\end{aligned}
$$

and the marginal condition for firing (in the bad state, i.e., a trough) is (as in a boom, this condition is satisfied in any trough. Thus, in the retention scenario it is satisfied although there is no firing)

$$
\begin{aligned}
& \operatorname{NMR}_{t}^{B}\left(Z^{B}, L_{t}^{B}\right)-\left[W^{0}+\frac{\mu}{1-\mu} k\right] \\
& +\delta\left[-P^{B} F+\left(1-P^{B}\right) H\right]=-F
\end{aligned}
$$

by (5), (7), and (12).

Having derived the labour demand function in the stochastic dynamic setting above, we now proceed to examine the employment effect of firing costs. We will analyze this effect first in the short run (i.e., the effect of firing costs on current employment in a boom and a trough) and then in the long run (i.e., the effect of firing costs on average employment, given the probabilities of being in booms and troughs). Finally, on this basis, we will examine how the influence of firing costs on employment depends on the degree of persistence of the booms and troughs. In the appendix we analyse the influence of hiring costs on employment.

\section{The Employment Effect of Firing Costs in the Short Run}

In order to assess the effect of firing costs on employment in booms and troughs, it is not necessary to consider a specific functional form of the revenue function: for any revenue function increasing and concave in $L$, the net marginal revenue is inversely related to the optimal level of employment. (Any variation in employment will produce a change of opposite sign in the marginal revenue, which is amplified through the feedback effect.)

To derive the effect of firing costs on employment in booms, we differentiate (10) with respect to the firing cost $F$ and obtain

$$
\frac{\partial N M R^{G}}{\partial F}=\delta\left(1-P^{G}\right)+\frac{\mu}{1-\mu}>0
$$

which is positive; that is, firing costs increase the net marginal revenue and consequently discourage hiring and thereby decrease employment. As (14) shows, this effect may be divided into two subsidiary effects:

(i) The direct effect $\delta\left(1-P^{G}\right)$ : with probability $\left(1-P^{G}\right)$ the firm encounters a bad state in the next time period and pays the firing cost, which discourages hiring in the current period. Observe that the more persistent is the boom (i.e., the larger is $P^{G}$ ), the smaller the influence of firing costs on the marginal revenue and consequently on current employment:

$$
\frac{\partial^{2} N M R^{G}}{\partial F \partial P^{G}}=-\delta<0 .
$$

(ii) The fall-back effect $\mu /(1-\mu)$ : a rise in the firing cost increases the negotiated wage (and thus reduces hiring) since it decreases the firm's fall-back position in wage bargaining. The greater is the worker's bargaining power $(\mu)$, the larger will be the fall-back effect.

Similarly, to derive the effect of firing costs on employment in troughs, we differentiate (13) with respect to the firing cost $F$ and find

$$
\frac{\partial N M R^{B}}{\partial F}=-\left(1-\delta P^{B}\right)<0
$$

This is the direct effect of firing costs: an increase in the cost of firing decreases the net marginal revenue, which discourages firing and thereby increases employment. The reason is that the cost of currently dismissing workers deters the firm from firing. (In this context, there is no fall-back effect of firing costs on the wage $\left(\partial W^{B} / \partial F=0\right)$, as shown in (7).) 
Observe that the more persistent is the trough (the greater the probability of remaining in the bad state), the smaller will be the effect of firing costs on the marginal revenue and consequently on employment:

$$
\frac{\partial^{2} N M R^{B}}{\partial F \partial P^{B}}=\delta>0
$$

by (16).

Thus, both hiring and firing are discouraged by the existence of firing costs; that is, firing costs decrease the variability of employment. However, the more persistent is the boom, the less is hiring discouraged, and the more persistent is the trough, the less is firing discouraged. This implies that more persistent economic conditions (either good or bad) weaken the effect of firing costs on employment and increase the variability of employment.

\section{The Employment Effect of Firing Costs in the Long Run and the Persistence of Economic Fluctuations}

In the long run, the employment level is

$$
E(L)=\Pi^{B} L^{G}+\Pi^{B} L^{B},
$$

where $\Pi^{G}$ and $\Pi^{B}$ are the long-run Markov probabilities for a good and a bad state, respectively. (The expressions for the long-run Markov probabilities for a good and a bad state are $\Pi^{G}=\left(1-P^{B}\right) /\left[\left(1-P^{G}\right)+\left(1-P^{B}\right)\right]$ and $\Pi^{B}=\left(1-P^{G}\right) /[(1-$ $\left.\left.P^{G}\right)+\left(1-P^{B}\right)\right]$, resp. ) Note that the proportion of troughs $\Pi^{B}$ is greater than the proportion of booms $\Pi^{G}$ since we are focusing on the case in which the persistence of troughs is greater than the persistence of booms $P^{B}>P^{G}$.

The effect of firing costs on long-term employment is $\partial E(L) / \partial F=\Pi^{G} \partial L^{G} / \partial F+\Pi^{B} \partial L^{B} / \partial F$. Since $\partial L^{i} / \partial F=$ $\left(\partial N M R^{i} / \partial F\right)\left(\partial L^{i} / \partial N M R^{i}\right)$, to study the effect of firing costs on long-run employment we need to refer to a specific revenue function. (The two components of $\partial L^{i} / \partial F$ are the effect of firing costs on the $N M R$ in each state of nature $\left(\partial N M R^{i} / \partial F\right)$, in (14) and (16), and the responsiveness of employment to a change in the NMR in each state of nature $\left(\partial L^{i} / \partial N M R^{i}, i=G, B\right)$. This last term (the inverse of the slope of the marginal revenue curve with respect to employment) clearly depends on the form of the revenue function.) Let us consider the following revenue function:

$$
R(L, Z)=Z^{i} L^{i}-\frac{1}{2} b\left(L^{i}\right)^{2}
$$

for which $N M R^{i}=Z^{i}-b /(1+\mu) L^{i}$. This is the simplest case, since $\partial L^{i} / \partial N M R^{i}=-(1+\mu) / b$, that is, the reaction of employment to a change in the NMR is constant for any state of nature. (We show in the appendix that the results presented in this section also hold for other revenue functions, in particular for a revenue function linear-quadratic in labor with multiplicative shocks and a Cobb-Douglas revenue function when turnover costs are sufficiently large.) Thus the demand for labour is linear with additive shocks. (This labor demand function is derived from (11) and (13), and from the expression for NMR.)

The effect of firing costs on employment in booms and troughs, respectively, is

$$
\begin{gathered}
\frac{\partial L^{G}}{\partial F}=-\frac{(1+\mu)}{b}\left[\delta\left(1-P^{G}\right)+\frac{\mu}{1-\mu}\right]<0 \\
\frac{\partial L^{B}}{\partial F}=\frac{(1+\mu)}{b}\left(1-\delta P^{B}\right)>0
\end{gathered}
$$

Therefore, the effect of firing costs on long-term employment is

$$
\begin{aligned}
\frac{\partial E(L)}{\partial F}=-\frac{(1+\mu)}{b}\{ & {\left[\Pi^{G} \delta\left(1-P^{G}\right)\right.} \\
& \left.\left.-\Pi^{B}\left(1-\delta P^{B}\right)\right]+\left[\Pi^{G} \frac{\mu}{1-\mu}\right]\right\},
\end{aligned}
$$

where the first term in square brackets is the direct effect and the second term in square brackets is the fall-back effect.

Observe in (21) that the direct effect of firing costs on average employment is positive because the firing cost is paid today (undiscounted) when the firm is firing whereas it may be paid tomorrow (discounted) when the firm is hiring. This qualitative conclusion is not affected by the proportion of troughs and booms. (The reason is that although we could expect a greater proportion of booms, which strengthens the hiring scenario, $P^{G}>P^{B}$ would also imply that the chances of firing the new recruits in the future are smaller. Thus, the effect of firing costs on the firing scenario dominates.)

Regarding the fall-back effect, observe that the negotiated wage in a boom depends on the firing cost whereas the wage in a trough does not (by (6) and (7)). An increase in the firing cost raises the wage in booms since it worsens the firm's fall-back position; but such an increase leaves the wage in troughs unaffected since the rise in the firing cost worsens the firm's fall-back position by just as much as it reduces the marginal product of labour. Thus the fall-back effect only appears in booms and its influence on employment is unambiguously negative: the greater are firing costs, the larger is the bargained wage in booms, which reduces hiring, as (21) shows.

The overall effect of the firing cost on average employment depends on the relative size of these two effects. This relative magnitude depends critically on two parameters: (i) the bargaining power of the worker and (ii) the persistence of economic conditions $\left(P^{G}\right.$ and $\left.P^{B}\right)$. Let us examine the effect of each parameter.

(i) How Employees' Bargaining Strength Influences the Employment Effect of Firing Costs. For a sufficiently large $\mu$, the fall-back effect of firing costs via the wage may offset the 


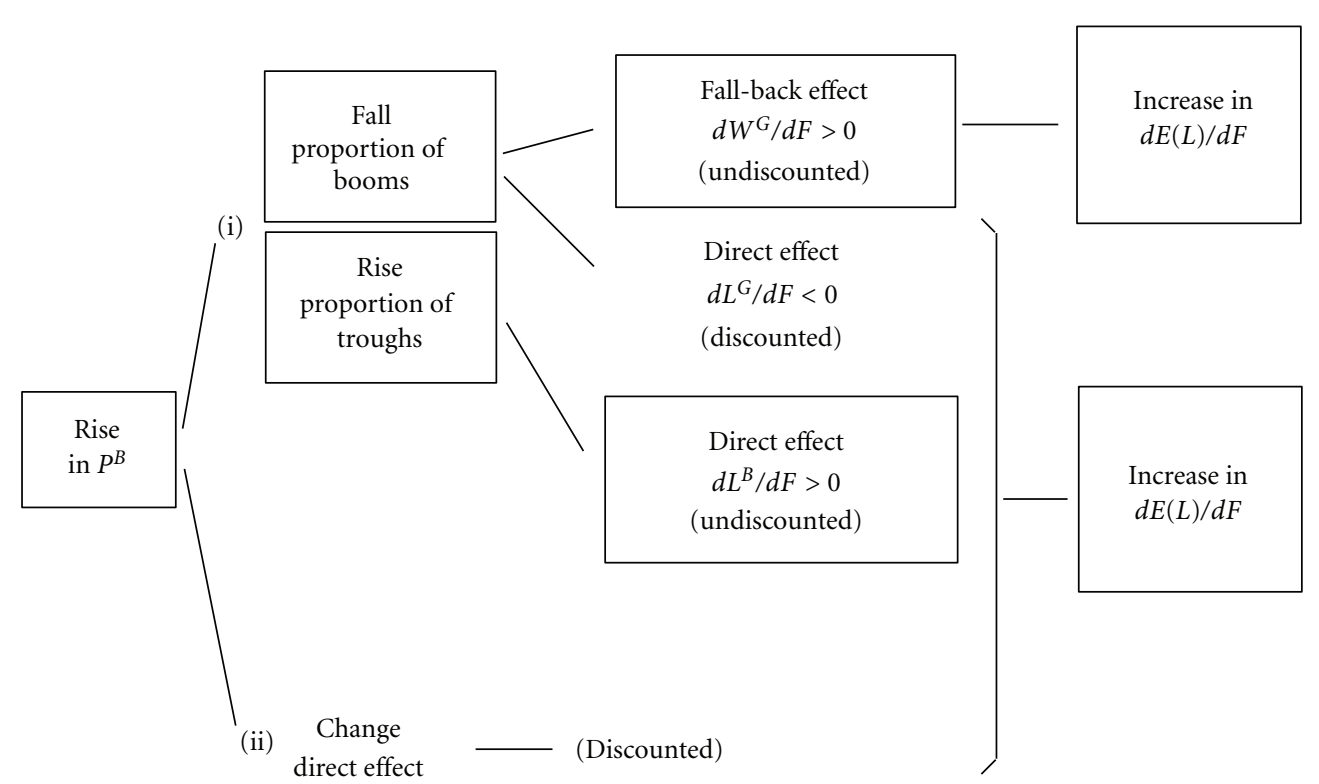

FIGURE 1: The influence of more persistent troughs on the employment effect of firing costs.

direct effect and make negative the influence of firing costs on average employment. This occurs for any $\mu$ that satisfies

$$
\mu>\mu^{*}=\frac{(1-\delta)\left(1-P^{G}\right)}{(1-\delta)\left(1-P^{G}\right)+\left(1-P^{B}\right)} .
$$

Note that the boundary $\mu^{*}$ from which the effect of firing costs on average employment is negative is larger the smaller is $P^{G}$ with respect to $P^{B}$. Thus, the greater is the proportion of troughs relative to booms, the greater is the bargaining power of the worker $\mu$ for which the effect of firing costs on average employment becomes negative.

(ii) How the Persistence of Economic Conditions Influences the Employment Effect of Firing Costs. We focus on the scenario in which troughs are more persistent than booms. We first show that the more persistent are troughs relative to booms, the more frequently the economy is in troughs and the less frequently in booms, and the more expansionary (or less contractionary) is the effect of firing costs on average employment. Then, we show that the frequency of troughs may also rise due to a proportional increase in the persistence of both booms and troughs, so that the influence of $F$ on $E(L)$ is more expansionary.

To prove that the more persistent are booms relative to troughs, the more expansionary is the effect of $F$ on average employment, we analyse the case in which troughs are more prolonged for given booms. (To prove the effect of more persistent troughs relative to booms, we can show that (a) the more persistent are troughs for given booms the more expansionary is the effect of firing costs on average employment, and (b) the less persistent are booms for given troughs the more expansionary is the effect of firing costs on average employment. In the appendix we prove (b) and show that the qualitative intuition is the same as for (a).) The influence of more persistent troughs is

$$
\begin{aligned}
\frac{\partial^{2} E(L)}{\partial F \partial P^{B}}= & -\frac{(1+\mu)}{b} \\
& \times\left\{\left[\frac{\partial \Pi^{G}}{\partial P^{B}} \delta\left(1-P^{G}\right)-\frac{\partial \Pi^{B}}{\partial P^{B}}\left(1-\delta P^{B}\right)\right]+\left[\delta \Pi^{B}\right]\right\} \\
& -\frac{(1+\mu)}{b}\left(\frac{\partial \Pi^{G}}{\partial P^{B}} \frac{\mu}{1-\mu}\right) .
\end{aligned}
$$

The first term (in the first and second rows of (23)) is the influence of the greater $P^{B}$ on the direct effect of firing costs, whereas the second term (in the third row) is the influence of the greater $P^{B}$ on the fall-back effect of firing costs.

From (21) and (23), it is clear that more persistent troughs (i.e., an increase in $P^{B}$ ) will influence the direct effect via the change in the following:

(i) the proportion of booms $\Pi^{G}$ and the proportion of troughs $\Pi^{B}$ (first term in curly brackets),

(ii) the employment effect of firing costs in troughs $\partial L^{B} / \partial F$ (second term in curly brackets), while the increase in $P^{B}$ will influence the fall-back effect via the change in $\Pi^{G}$ (third row).

We describe these terms below and use Figure 1 to illustrate the analysis.

(i) Regarding the change in the proportions of booms and troughs, it is clear that a greater persistence of troughs (an increase in $P^{B}$ ) will augment the proportion of troughs $\Pi^{B}$ and reduce the proportion of booms $\Pi^{G}$. This is represented by (i) in Figure 1. 


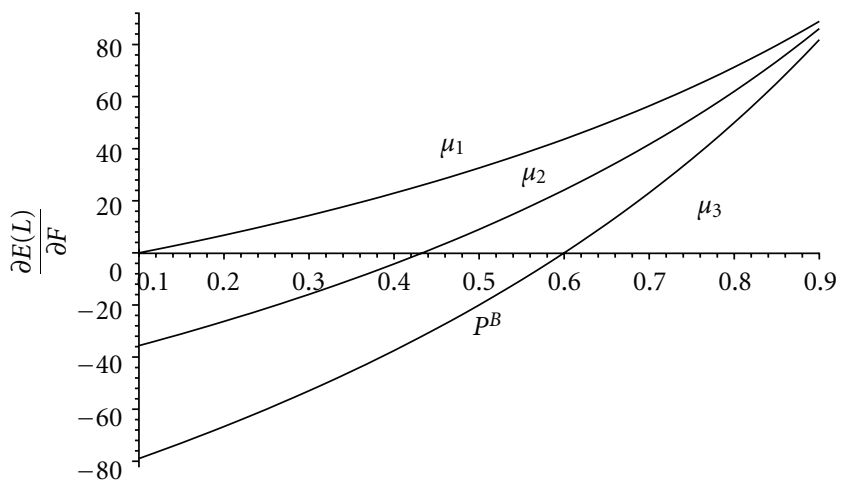

Figure 2: The influence of $P^{B}$ on $\partial E(\mathrm{~L}) / \partial F$.

The implication for the direct effect is the following: the increase in the proportion of troughs implies, on the one hand, a decrease in the frequency with which the firm's hiring is discouraged by firing costs (due to the possibility of paying $F$ in the future). Additionally, the greater proportion of troughs increases the frequency with which the firm retains workers in order to avoid paying the firing cost (observe that this effect is undiscounted). As a consequence, the rise in $\Pi^{B}$ and the fall in $\Pi^{G}$ increase the positive direct effect.

(ii) Regarding the change in the direct effect of $F$ in troughs, we showed in (17) that more persistent economic conditions will weaken $\partial L^{B} / \partial F$. (Recall that, in the firing scenario, a greater $P^{B}$ increases the probability of retaining the marginal worker in the future, with profitability $-F$.) Note that this effect depends on the discount factor $\delta$. This term is represented by the last line of Figure 1.

Regarding the fall-back effect, it is only influenced by the greater $P^{B}$ via the change in the proportions of booms and troughs $\left(\Pi^{G}\right.$ and $\left.\Pi^{B}\right)$. The greater proportion of troughs implies that the firm is less frequently paying the wage in booms (which is higher due to firing costs). Thus, the rise in $P^{B}$ reduces the negative fall-back effect. The first row of Figure 1 represents it.

Solving (23), we obtain that

$$
\begin{aligned}
\frac{\partial^{2} E(L)}{\partial F \partial P^{B}}= & \frac{(1+\mu)}{b} \frac{\left(1-P^{G}\right)}{\left[\left(1-P^{G}\right)+\left(1-P^{B}\right)\right]^{2}} \\
& \times\left[(1-\delta)+\frac{\mu}{1-\mu}\right]>0 .
\end{aligned}
$$

The first term in square brackets $(1-\delta)$ is related to the influence of $P^{B}$ on the direct effect and is positive; that is, the more persistent are recessions, the more positive is the direct effect of firing costs on average employment. This means that what dominates here is effect (i) (via the change in the proportions $\Pi^{G}$ and $\Pi^{B}$ ). The reason is that the greater frequency with which the firm retains workers to avoid the firing costs is undiscounted while, in contrast, effect (ii) (via the change in the employment level) is discounted. The second term in square brackets $(\mu /(1-\mu))$ is related to the influence of $P^{B}$ on the fall-back effect (i.e., the more persistent are troughs, the less negative is the fall-back effect of firing costs on average employment). Figure 2 illustrates the result. In Figure 1 we represent in boxes the mechanisms that determine the increase in $\partial E(L) / \partial F$.

Now we show that the frequency of troughs relative to booms may also rise due to a proportional increase in the persistence of both booms and troughs. As a consequence, we show that the qualitative conclusions reached for more persistent troughs also apply in the case of more persistent economic fluctuations.

Differentiating (21) with respect to $P^{G}$ and $P^{B}$, the effect of more persistent booms and troughs (i.e., the greater persistence of economic fluctuations) is $\left(\partial^{2} E(L) / \partial F \partial P=\partial^{2} E(L) /\right.$ $\left.\partial F \partial P^{G}+\partial^{2} E(L) / \partial F \partial P^{B}\right)$ :

$$
\begin{aligned}
\frac{\partial^{2} E(L)}{\partial F \partial P}=- & \frac{(1+\mu)}{b}\left\{\left[\frac{\partial \Pi^{G}}{\partial P} \delta\left(1-P^{G}\right)-\frac{\partial \Pi^{B}}{\partial P}\left(1-\delta P^{B}\right)\right]\right. \\
& \left.-\left[\delta \Pi^{G}-\delta \Pi^{B}\right]\right\} \\
& -\frac{(1+\mu)}{b}\left\{\frac{\partial \Pi^{G}}{\partial P} \frac{\mu}{1-\mu}\right\},
\end{aligned}
$$

where $\partial \Pi^{i} / \partial P=\partial \Pi^{i} / \partial P^{G}+\partial \Pi^{i} / \partial P^{B}$. The first term (in the first and second rows of (25)) is the influence of the greater $P$ on the direct effect of firing costs, whereas the second term (in the third row) is the influence of the greater $P$ on the fall-back effect of firing costs.

As for the greater $P^{B}$, the greater $P$ influences $\partial E(L) / \partial F$ (i) via the change in the proportions of booms and troughs $\left(\Pi^{G}\right.$ and $\Pi^{B}$ ), represented by the first term in curly brackets in the first row and by the second row, and (ii) via the change in the direct effect in booms and the direct effect in troughs, 
represented by the second term in curly brackets in the first row.

(i) Regarding the change in the proportions of booms and troughs, a simultaneous increase in $P^{G}$ and $P^{B}$ changes the proportion of booms in the following way (it is clear that a greater persistence of booms (an increase in $P^{G}$ ) will augment the proportion of booms $\Pi^{G}$; the magnitude depends on the probability of the economy leaving troughs and moving into booms $\left(1-P^{B}\right)$. On the other hand, a greater persistence of troughs (an increase in $P^{B}$ ) will reduce $\Pi^{G}$; the magnitude depends on the probability of the economy leaving booms and moving into troughs $\left.\left(1-P^{G}\right)\right)$ :

$$
\begin{aligned}
& \frac{\partial \Pi^{G}}{\partial P^{G}}=\frac{\left(1-P^{B}\right)}{\left[\left(1-P^{G}\right)+\left(1-P^{B}\right)\right]^{2}}>0 ; \\
& \frac{\partial \Pi^{G}}{\partial P^{B}}=-\frac{\left(1-P^{G}\right)}{\left[\left(1-P^{G}\right)+\left(1-P^{B}\right)\right]^{2}}<0 .
\end{aligned}
$$

Thus, the net influence of a simultaneous increase in $P^{G}$ and $P^{B}$ on the proportion of booms is

$$
\frac{\partial \Pi^{G}}{\partial P}=\frac{\left(P^{G}-P^{B}\right)}{\left[\left(1-P^{G}\right)+\left(1-P^{B}\right)\right]^{2}}<0 \quad \text { for } P^{B}>P^{G} .
$$

If the persistence of booms and troughs was symmetric (i.e. equal $P^{G}$ and $P^{B}$ ), a proportional increase in $P^{G}$ and $P^{B}$ would generate two counteracting effects which will cancel out: $\Pi^{G}$ would not change. In contrast, in the case in which $P^{B}>P^{G}$, the probability of the economy moving from a trough to a boom $\left(1-P^{B}\right)$ is smaller than the probability of moving from a boom to a trough $\left(1-P^{G}\right)$. Therefore, the economy is more likely to be in troughs and the effect of the increase in $P^{B}$ dominates (i.e., the proportion of booms decreases). Similarly, in the case of the proportion of recessions $\Pi^{B}$ (by the expressions for the long-run Markov probabilities, $\partial \Pi^{B} / \partial P^{G}=-\partial \Pi^{G} / \partial P^{G}$ and $\left.\partial \Pi^{B} / \partial P^{B}=-\partial \Pi^{G} / \partial P^{B}\right)$ :

$$
\frac{\partial \Pi^{B}}{\partial P}=-\frac{\left(P^{G}-P^{B}\right)}{\left[\left(1-P^{G}\right)+\left(1-P^{B}\right)\right]^{2}}>0 \text { for } P^{G}<P^{B} .
$$

Thus, a simultaneous increase in $P^{G}$ and $P^{B}$ raises the proportion of troughs and reduces the proportion of booms, for $P^{B}>$ $P^{G}$ (note that it is unimportant if the difference between $P^{G}$ and $P^{B}$ is proportional or additive). This is represented by the second row of Figure 1, and has the same consequence as the increase in $P^{B}$ : the rise in $\Pi^{B}$ and the fall in $\Pi^{G}$ increase the positive direct effect and weaken the negative fall-back effect. This is the influence that dominates since it is undiscounted.

(ii) Regarding the change in the direct effect in booms and the direct effect in troughs, this effect is discounted and does not determine the sign of the result.
(As to the change in the direct effect in booms and the direct effect in troughs, we showed in Section 2 that more persistent economic conditions will weaken both $\partial L^{G} / \partial F$ and $\partial L^{B} / \partial F$. On the other hand, $L^{G}$ is higher since a more persistent boom reduces the probability of firing in the future and bearing the firing cost: $\partial^{2} L^{G} / \partial F \partial P^{G}=\delta((1+\mu) / b)>0$. Additionally, $L^{B}$ is lower since a greater $P^{B}$ increases the possibility of retaining workers in the future with a marginal profit of $-F: \partial^{2} L^{B} / \partial F \partial P^{B}=-\delta((1+\mu) / b)<$ 0 . As the proportion of troughs is greater than the proportion of booms $\Pi^{B}>\Pi^{G}$, what happens in troughs dominates. Note that these effects depend on the discount factor $\delta$. This term is represented by the last line of Figure 1.)

Figure 1 is also useful to illustrate this result since the qualitative intuition is the same as in the case of a greater persistence of troughs.

Solving (25), we obtain that

$$
\begin{aligned}
\frac{\partial^{2} E(L)}{\partial F \partial P}= & -\frac{(1+\mu)}{b} \frac{\left(P^{G}-P^{B}\right)}{\left[\left(1-P^{G}\right)+\left(1-P^{B}\right)\right]^{2}} \\
& \times\left[(1-\delta)+\left(\frac{\mu}{1-\mu}\right)\right]>0 .
\end{aligned}
$$

The first term in square brackets $(1-\delta)$ is related to the influence of $P$ on the direct effect and the second term $(\mu /(1-$ $\mu)$ ) to the influence on the fall-back effect. As (29) shows, both terms are positive; that is, the more persistent are economic fluctuations, the more expansionary is the effect of firing costs on average employment (when $P^{G}<P^{B}$ ). As in the case of more prolonged troughs, the greater proportion of troughs, and the lower proportion of booms increases the positive direct effect of firing costs. Additionally, the smaller proportion of booms makes the firm to pay less often the wage $W^{G}$, which reduces the negative fall-back effect. Observe that the results above are stronger the wider is the difference between the persistence of troughs and the persistence of booms.

\section{Conclusions}

This paper studies the influence of turnover costs on average labour demand when the persistence of recessions is greater than the persistence of booms. In doing so, we also take into account the influence of turnover costs on the negotiated wage. We show that the more persistent are troughs relative to booms, the more frequently firms are in a situation where firing costs discourage firing and so the more positive is the effect of firing costs on labour demand. In this way, when an economy is suffering more prolonged recessions (relative to booms), our analysis suggests that a reduction in firing costs will also reduce average labour demand. 


\section{Appendices}

\section{A. Revenue Function Linear Quadratic in Labour with Additive Shocks}

A.1. Firing Costs. We prove that the less persistent are booms relative to troughs, the more expansionary is the effect of firing costs on average employment:

$$
\begin{aligned}
-\frac{\partial^{2} E(L)}{\partial F \partial P^{G}}= & \frac{(1+\mu)}{b} \frac{\left(1-P^{B}\right)}{\left[\left(1-P^{G}\right)+\left(1-P^{B}\right)\right]^{2}} \\
& \times\left[(1-\delta)+\frac{\mu}{1-\mu}\right]>0 .
\end{aligned}
$$

\section{A.2. Hiring Costs}

A.2.1. Short Run. The effect of hiring costs on employment in booms is, by (10),

$$
\frac{\partial L^{G}}{\partial H}=-\frac{(1+\mu)}{b}\left[\left(1-\delta P^{G}\right)+\frac{\mu}{1-\mu}\right]<0 .
$$

This effect may be divided into two subsidiary effects.

(i) The direct effect $\left(1-\delta P^{G}\right)$ : hiring costs discourage hiring. However, the greater is $P^{G}$, the less important is the fixed cost of hiring:

$$
\frac{\partial^{2} L^{G}}{\partial H \partial P^{G}}=\delta>0 .
$$

(ii) The profitability effect $\mu /(1-\mu)$ : the cost of hiring increases the marginal profit of the worker, and he can obtain a higher wage in the negotiation. The greater is $\mu$, the larger will be the profitability effect.

The effect of hiring costs on employment in troughs is, from (13),

$$
\frac{\partial L^{B}}{\partial F}=\frac{(1+\mu)}{b}\left(1-\delta P^{B}\right)>0,
$$

that is, hiring costs discourage firing: the higher the cost of hiring the more workers will be retained in bad times to avoid the hiring cost if economic conditions improve. The greater is $P^{B}$ the less important is this effect:

$$
\frac{\partial^{2} L^{B}}{\partial H \partial P^{B}}=-\delta<0
$$

by (A.4).

A.2.2. Long Run. The effect of hiring costs on long-term employment is

$$
\begin{aligned}
\frac{\partial E(L)}{\partial H}=-\frac{(1+\mu)}{b}\{[ & {\left[\Pi^{G}\left(1-\delta P^{G}\right)-\Pi^{B} \delta\left(1-P^{B}\right)\right] } \\
+ & {\left.\left[\Pi^{G} \frac{\mu}{1-\mu}\right]\right\}, }
\end{aligned}
$$

where the first term in square brackets is the direct effect and the second term in square brackets is the profitability effect. The direct effect of hiring costs on average employment may be positive or negative, depending on $\delta$. Regarding the profitability effect, the negotiated wage in a boom depends on the hiring cost whereas the wage in a trough does not (by (6) and (7)). The overall effect of the firing cost on average employment depends on the relative size of these two effects, which in turn depends on $\mu, P^{G}$ and $P^{B}$.

(i) How employees' bargaining strength influences the employment effect of hiring costs: since the profitability effect is formally identical to the fall-back effect, the qualitative result in the case of firing costs holds also in the case of hiring costs.

(ii) How the persistence of economic conditions influences the employment effect of firing costs.

These equations are very similar to the case of firing costs. The influence of less persistent booms is

$$
\begin{aligned}
-\frac{\partial^{2} E(L)}{\partial H \partial P^{G}}= & \frac{(1+\mu)}{b} \frac{\left(1-P^{B}\right)}{\left[\left(1-P^{G}\right)+\left(1-P^{B}\right)\right]^{2}} \\
& \times\left[(1-\delta)+\frac{\mu}{1-\mu}\right]>0 .
\end{aligned}
$$

The influence of more persistent troughs is

$$
\begin{aligned}
\frac{\partial^{2} E(L)}{\partial H \partial P^{B}}= & \frac{(1+\mu)}{b} \frac{\left(1-P^{G}\right)}{\left[\left(1-P^{G}\right)+\left(1-P^{B}\right)\right]^{2}} \\
& \times\left[(1-\delta)+\frac{\mu}{1-\mu}\right]>0 .
\end{aligned}
$$

The effect of more prolonged booms and troughs is

$$
\begin{aligned}
\frac{\partial^{2} E(L)}{\partial H \partial P}= & -\frac{(1+\mu)}{b} \frac{\left(P^{G}-P^{B}\right)}{\left[\left(1-P^{G}\right)+\left(1-P^{B}\right)\right]^{2}} \\
& \times\left[(1-\delta)+\left(\frac{\mu}{1-\mu}\right)\right]>0,
\end{aligned}
$$

that is, the more persistent are economic fluctuations, or the more persistent are troughs relative to booms, the more expansionary is the effect of hiring costs on average employment (when $P^{B}>P^{G}$ ).

\section{B. Revenue Function Linear-Quadratic in Labour with Multiplicative Shocks and Cobb-Douglas Production Function}

The effect of firing costs on long-term employment is

$$
\begin{aligned}
\frac{\partial E(L)}{\partial F}= & {\left[\Pi^{G} \delta\left(1-P^{G}\right) \frac{\partial L^{G}}{\partial N M R^{G}}\right.} \\
& \left.-\Pi^{B}\left(1-\delta P^{B}\right) \frac{\partial L^{B}}{\partial N M R^{B}}\right]+\Pi^{G} \frac{\mu}{1-\mu} \frac{\partial L^{G}}{\partial N M R^{G}},
\end{aligned}
$$


where the first term (with square brackets) is the direct effect and the second term (without brackets) is the fall-back effect. The term $\partial L^{i} / \partial N M R^{i}$ depends on the form of the revenue function. We consider two additional revenue functions.

(a) $(L, Z)=Z^{i}\left(L^{i}-b / 2\left(L^{i}\right)^{2}\right)$, for which $N M R^{i}=Z(1-b /$ $\left.(1+\mu) L^{i}\right)$. In this case, $\partial L^{i} / \partial N M R^{i}=-(1+\mu) / Z^{i} b$, that is, the reaction of employment to a change in the NMR depends on the state of nature $Z^{i}$ : since $Z^{G}>Z^{B}, L^{B}$ is more responsive than $L^{G}$ to an identical change in the $N M R\left(\left|\partial L^{G} / \partial N M R^{G}\right|<\left|\partial L^{B}\right|\right.$ $\left.\partial N M R^{B} \mid\right)$.

(b) $R(L, Z)=Z^{i}\left(L^{i(1-\beta)} /(1-\beta)\right)($ Cobb-Douglas revenue function). Thus $N M R^{i}=Z^{i} L^{i(-\beta)}[1+\beta \mu /(1+\mu)]$; that is, the $N M R$ is convex in employment. In this case, the responsiveness of employment to a change in the $N M R$ is $\partial L^{i} / \partial N M R^{i}=-L^{i(\beta+1)} /\left\{Z^{i} \beta[1+\beta \mu /(1+\right.$ $\mu)]\}$. Observe that, for the Cobb-Douglas revenue function, the relative magnitude of $\partial L^{G} / \partial N M R^{G}$ with respect to $\partial L^{B} / \partial N M R^{B}$ depends not only on the business conditions $Z^{i}$, but also on the employment levels $L^{G}$ and $L^{B}$. We derive the levels of employment from the first-order condition in (8) and (12) and the NMR:

$$
\begin{aligned}
& L_{t}^{G}=\left(\frac{W_{t}^{G}-\delta P^{G} H+\delta\left(1-P^{G}\right) F+H}{Z^{G}(1+\beta \mu /(1+\mu))}\right)^{-1 / \beta}, \\
& L_{t}^{B}=\left(\frac{W_{t}^{B}-\delta\left(1-P^{B}\right) H+\delta P^{B} F+H}{Z^{G}(1+\beta \mu /(1+\mu))}\right)^{-1 / \beta} .
\end{aligned}
$$

$L^{G}$ must be greater than $L^{B}$, which implies that

$$
\begin{aligned}
\frac{Z^{G}}{Z^{B}}>( & \left(W^{0}+\mu /(1-\mu)(H+F+k)-\delta P^{G} H\right. \\
& \left.+\delta\left(1-P^{G}\right) F+H\right) \\
\times & \left(W^{0}+\mu /(1-\mu) k-\delta\left(1-P^{B}\right) H\right. \\
& \left.\left.+\delta P^{B} F-F\right)^{-1}\right) .
\end{aligned}
$$

Recall from Section 1 that the higher $F$ and $H$, the more employment is stabilized over the cycle, and the closer are $L^{G}$ and $L^{B}$. Thus, when $L^{G}$ and $L^{B}$ are sufficiently close (i.e., turnover costs sufficiently high relative to $\left(Z^{G}-Z^{B}\right)$ ), it may happen that $\left|\partial L^{G} / \partial N M R^{G}\right|<\left|\partial L^{B} / \partial N M R^{B}\right|$. This inequality is satisfied when

$$
\begin{aligned}
\frac{Z^{G}}{Z^{B}}<( & \left(W^{0}+\mu /(1-\mu)(H+F+k)-\delta P^{G} H\right. \\
& \left.+\delta\left(1-P^{G}\right) F+H\right) \\
& \left.\times\left(W^{0}+\mu /(1-\mu) k-\delta\left(1-P^{B}\right) H+\delta P^{B} F-F\right)^{-1}\right)^{(\beta+1)}
\end{aligned}
$$

In contrast, when $L^{G}$ and $L^{B}$ are sufficiently different (turnover costs sufficiently low), it may happen that $\mid \partial L^{G} /$ $\partial N M R^{G}|>| \partial L^{B} / \partial N M R^{B} \mid$ (the inequality in (B.4) must hold in the opposite direction). Thus, for sufficiently large turnover costs, the Cobb- Douglas revenue function satisfies the following condition: $\left|\partial L^{G} / \partial N M R^{G}\right| \leq\left|\partial L^{B} / \partial N M R^{B}\right|$. (This condition also depends on the persistence of macroeconomic fluctuations since the more prolonged is the boom the higher is employment in a good state, and the more prolonged is the trough, the lower is employment in the bad state. Observe in the expressions for $L^{G}$ and $L^{B}$ that, in the absence of turnover costs, the persistence of the shock has no influence on employment.)

Regarding the direct effect in (B.1), when $\mid \partial L^{G} /$ $\partial N M R^{G}|\leq| \partial L^{B} / \partial N M R^{B} \mid$, the direct effect of firing costs on average employment is positive. When $\left|\partial L^{G} / \partial N M R^{G}\right|>$ $\left|\partial L^{B} / \partial N M R^{B}\right|$ (the case of the Cobb-Douglas revenue function with low turnover costs), the direct effect may become negative since the hiring scenario becomes more important. The fall-back effect is negative. The overall effect of the firing cost on average employment depends on the relative size of these two effects, which depends on $\mu$ and $P^{G}$ and $P^{B}$. Let us examine the results above for each production function.

We show that the effect of $F$ on $E(L)$ is more expansionary, when $\left|\partial L^{G} / \partial N M R^{G}\right| \leq\left|\partial L^{B} / \partial N M R^{B}\right|$ and $P^{B}>P^{G}$, the greater is the persistence of economic fluctuations and the more prolonged are troughs.

B.1. Revenue Function Linear-Quadratic in Labour with Multiplicative Shocks. The effect of firing costs on average employment equals, by (B.1),

$$
\begin{aligned}
\frac{\partial E(L)}{\partial F}= & {\left[-\Pi^{G} \delta\left(1-P^{G}\right) \frac{(1+\mu)}{Z^{G} b}+\Pi^{B}\left(1-\delta P^{B}\right) \frac{(1+\mu)}{Z^{B} b}\right] } \\
& -\Pi^{G} \frac{\mu}{1-\mu} \frac{(1+\mu)}{Z^{G} b},
\end{aligned}
$$

$\partial E(L) / \partial F$ is smaller than 0 when

$$
\begin{aligned}
\mu>\mu^{*}= & \left(\left(1-P^{G}\right)\left[Z^{G}\left(1-\delta P^{B}\right)-Z^{B} \delta\left(1-P^{B}\right)\right]\right) \\
& \times\left(\left(1-P^{G}\right)\left[Z^{G}\left(1-\delta P^{B}\right)-Z^{B} \delta\left(1-P^{B}\right)\right]\right. \\
& \left.+Z^{B}\left(1-P^{B}\right)\right)^{-1} \cdot
\end{aligned}
$$


The effect of a greater persistence of economic conditions is

$$
\begin{aligned}
\frac{\partial^{2} E(L)}{\partial F \partial P}=-\frac{(1+\mu)}{Z^{G} Z^{B} b}\left[\frac{\partial \Pi^{G}}{\partial P} Z^{B} \delta\left(1-P^{G}\right)\right. \\
\left.+\frac{\partial \Pi^{B}}{\partial P} Z^{G}\left(1-\delta P^{B}\right)\right] \\
-\frac{(1+\mu)}{Z^{G} Z^{B} b}\left[\frac{\partial \Pi^{G}}{\partial P} Z^{B} \frac{\mu}{1-\mu}-\delta\left(Z^{B} \Pi^{G}-Z^{G} \Pi^{B}\right)\right]
\end{aligned}
$$

which rearranging is

$$
\begin{aligned}
& \frac{\partial^{2} E(L)}{\partial F \partial P}= \frac{Z^{B} \delta\left[\left(1-P^{G}\right)^{2}+\left(1-P^{B}\right)^{2}\right]}{\left(b\left[\left(1-P^{G}\right)+\left(1-P^{B}\right)\right] Z^{G} Z^{B}\right) /(1+\mu)} \\
&-\left(Z ^ { G } \left[\delta\left(1-P^{G}\right)^{2}+\left(1-P^{B}\right)\left(1-\delta P^{B}\right)\right.\right. \\
&\left.\left.-\left(1-P^{G}\right)(1-\delta)\right]\right) \\
& \quad \times\left(b\left[\left(1-P^{G}\right)+\left(1-P^{B}\right)\right] Z^{G} Z^{B} /(1+\mu)\right)^{-1}>0 .
\end{aligned}
$$

This expression is positive. Recall from the text that for the revenue function for which $\left|\partial L^{G} / \partial N M R^{G}\right|=\left|\partial L^{B} / \partial N M R^{B}\right|$, the more persistent the fluctuations the more expansionary is the effect of $F$ on $E(L)$ (when $P^{B}>P^{G}$ ) because the greater persistence increases the proportion of troughs and therefore increases the importance of the positive direct effect of $F$ on employment in troughs (which is undiscounted). As shown above, for the revenue function linear-quadratic in labour with multiplicative shocks $\left|\partial L^{G} / \partial N M R^{G}\right|<\left|\partial L^{B} / \partial N M R^{B}\right|$. Given that the bad state is more important in relative terms, the increase in the proportion of troughs is also the effect that dominates. The intuition is the same as in the case of a revenue function liner-quadratic in labour with additive shocks.

This explanation also applies for the case of more persistent troughs:

$$
\begin{aligned}
\frac{\partial^{2} E(L)}{\partial F \partial P^{B}}= & \frac{(1+\mu)}{Z^{G} Z^{B} b} \\
& \times\left(( 1 - P ^ { G } ) \left[Z^{B} \delta\left(1-P^{G}\right)+Z^{B}(\mu /(1-\mu))\right.\right. \\
& \left.\left.\quad+Z^{G}\left(1-\delta P^{B}\right)\right]\right) \\
& \times\left(\left[\left(1-P^{G}\right)+\left(1-P^{B}\right)\right]^{-2}\right) \\
& -\frac{(1+\mu)}{Z^{G} Z^{B} b} \delta Z^{G} \Pi^{B}
\end{aligned}
$$

$$
\begin{aligned}
& =\frac{(1+\mu)}{Z^{G} Z^{B} b} \\
& \quad \times\left(( 1 - P ^ { G } ) \left[Z^{B} \delta\left(1-P^{G}\right)+Z^{B}(\mu /(1-\mu))\right.\right. \\
& \left.\left.\quad+Z^{G}\left(1-\delta\left(2-P^{G}\right)\right)\right]\right) \\
& \quad \times\left(\left[\left(1-P^{G}\right)+\left(1-P^{B}\right)\right]^{-2}\right) .
\end{aligned}
$$

This equation is positive when $Z^{G} /\left(Z^{G}-Z^{B}\right)<\delta\left(1-P^{G}\right) /(1-$ $\delta)$. As to less persistent booms:

$$
\begin{aligned}
-\frac{\partial^{2} E(L)}{\partial F \partial P^{G}}= & \frac{(1+\mu)}{Z^{G} Z^{B} b} \\
& \times\left(( 1 - P ^ { B } ) \left[Z^{B} \delta\left(1-P^{G}\right)+Z^{B}(\mu / 1-\mu)\right.\right. \\
& \left.\left.-Z^{G}\left(1-\delta P^{B}\right)\right]\right) \\
& \times\left(\left[\left(1-P^{G}\right)+\left(1-P^{B}\right)\right]^{-2}\right) \\
& -\frac{(1+\mu)}{Z^{G} Z^{B} b} \delta Z^{B} \Pi^{G} \\
= & \left(( 1 - P ^ { B } ) \left[Z^{B} \delta\left(1-P^{B}\right)+Z^{B}(\mu / 1-\mu)\right.\right. \\
& +\left(Z^{G} Z^{B} b\left[\left(1-P^{G}\right)+\left(1-P^{B}\right)\right]^{2} /(1+\mu)\right)^{-1} \\
& >0 .
\end{aligned}
$$

B.2. Cobb-Douglas Revenue Function. The effect of $F$ on $E(L)$ is

$$
\begin{aligned}
\frac{\partial E(L)}{\partial F}= & -\frac{\Pi^{G} L^{G(\beta+1)}\left[\delta\left(1-P^{G}\right)+\mu /(1-\mu)\right]}{Z^{G} \beta[1+\beta \mu /(1+\mu)]} \\
& +\frac{\Pi^{B} L^{B(\beta+1)}\left(1-\delta P^{B}\right)}{Z^{B} \beta[1+\beta \mu /(1+\mu)]} .
\end{aligned}
$$


Regarding the persistence of the fluctuations, the general expression is

$$
\begin{aligned}
\frac{\partial^{2} E(L)}{\partial F \partial P}= & \left\{-\delta \Pi^{G}+\frac{\partial \Pi^{G}}{\partial P}\left[\delta\left(1-P^{G}\right)+\frac{\mu}{1-\mu}\right]\right\} \\
& \times \frac{\partial L^{G}}{\partial N M R^{G}}-\left[-\delta \Pi^{B}+\frac{\partial \Pi^{B}}{\partial P}\left(1-\delta P^{B}\right)\right] \\
& \times \frac{\partial L^{B}}{\partial N M R^{B}} \\
& +\left\{\Pi^{G}\left[\delta\left(1-P^{G}\right)+\mu /(1-\mu)\right]\right\} \frac{\partial L^{G}}{\partial N M R^{G} \partial P^{G}} \\
& -\Pi^{B}\left(1-\delta P^{B}\right) \frac{\partial L^{B}}{\partial N M R^{B} \partial P^{B}} .
\end{aligned}
$$

The first three rows of (B.12) are the same for any of the production functions. The last two lines appear only for the Cobb-Douglas revenue function since $\partial L^{i} / \partial N M R^{i}$ depends on the persistence of the fluctuations. These are relatively small effects and do not determine the result. We concentrate in the first two lines.

For the Cobb-Douglas revenue function there are two scenarios (described above): (i) for sufficiently large turnover costs the condition $\left|\partial L^{G} / \partial N M R^{G}\right|<\left|\partial L^{B} / \partial N M R^{B}\right|$ is satisfied, while (ii) for sufficiently small turnover costs the condition $\left|\partial L^{G} / \partial N M R^{G}\right|>\left|\partial L^{B} / \partial N M R^{B}\right|$ is satisfied.

(i) This case is qualitatively the same as the case of the revenue function linear quadratic in labour with multiplicative shocks.

(ii) In this case employment in booms is more responsive to a given change in the NMR. Regarding the direct effect, for the increase in the proportion of troughs (and the increase in the importance of the undiscounted positive effect of $F$ on employment in firing times) to dominate, it is necessary that the discount factor $\delta$ is sufficiently large.

The influence of less persistent booms is

$$
\begin{aligned}
-\frac{\partial^{2} E(L)}{\partial F \partial P^{G}}= & -\left\{-\delta \Pi^{G}+\frac{\partial \Pi^{G}}{\partial P^{G}}\left[\delta\left(1-P^{G}\right)+\frac{\mu}{1-\mu}\right]\right\} \\
& \times \frac{\partial L^{G}}{\partial N M R^{G}}+\left[\frac{\partial \Pi^{B}}{\partial P^{G}}\left(1-\delta P^{B}\right)\right] \frac{\partial L^{B}}{\partial N M R^{B}} \\
& -\left\{\Pi^{G}\left[\delta\left(1-P^{G}\right)+\mu /(1-\mu)\right]\right\} \\
& \times \frac{\partial L^{G}}{\partial N M R^{G} \partial P^{G}} .
\end{aligned}
$$

The explanation of the sign of (B.13) is identical to the explanation of the sign of (B.12).
The influence of more persistent troughs is

$$
\begin{aligned}
\frac{\partial^{2} E(L)}{\partial F \partial P^{B}}= & \left\{\frac{\partial \Pi^{G}}{\partial P^{B}}\left[\delta\left(1-P^{G}\right)+\frac{\mu}{1-\mu}\right]\right\} \frac{\partial L^{G}}{\partial \mathrm{NMR}^{G}} \\
& -\left[-\delta \Pi^{B}+\frac{\partial \Pi^{B}}{\partial P^{B}}\left(1-\delta P^{B}\right)\right] \frac{\partial L^{B}}{\partial \mathrm{NMR}^{B}} \\
& -\Pi^{B}\left(1-\delta P^{B}\right) \frac{\partial L^{B}}{\partial \mathrm{NMR}^{B} \partial P^{B}} .
\end{aligned}
$$

Regarding (B.14), we need to differentiate between two scenarios:

(i) Sufficiently large turnover costs: this case is qualitatively the same as the case of the revenue function linear quadratic in labour with multiplicative shocks.

(ii) Sufficiently small turnover costs: given that employment in booms is more responsive, the reduction in the proportion of booms is the effect that dominates. Thus the qualitative result is the same as for the revenue function linear quadratic in labour with additive shocks.

\section{References}

[1] OECD, Employment Outlook 2004, Organisation for Economic Co-operation and Development, 2004.

[2] R. Layard, S. Nickell, and R. Jackman, Unemployment: Macroeconomic Performance and the Labor Market, Oxford University Press, Oxford, UK, 1991.

[3] E. P. Lazear, "Job security provisions and employment," Quarterly Journal of Economics, vol. 105, no. 3, pp. 699-726, 1990.

[4] G. Bertola, "Job security, employment and wages," European Economic Review, vol. 34, no. 4, pp. 851-886, 1990.

[5] H. A. Hopenhayn and R. Rogerson, "Job turnover and policy evaluation: a general equilibrium approach," Journal of Political Economy, vol. 101, no. 5, pp. 915-938, 1993.

[6] S. Nickell, "Unemployment and labor market rigidities: Europe versus North America," Journal of Economic Perspectives, vol. 11, no. 3, pp. 55-74, 1997.

[7] J. Heckman and C. Pages, "The cost of job security regulation: evidence from Latin American labor markets," NBER Working Paper 7773, 2000.

[8] S. Bentolila and G. Bertola, "Firing costs and labor demand: how bad is eurosclerosis?” Review of Economic Studies, vol. 57, no. 3, pp. 381-402, 1990.

[9] G. Bertola, "Labor turnover costs and average labor demand," Journal of Labor Economics, vol. 10, pp. 389-411, 1992.

[10] S. Bentolila and G. Saint-Paul, "A model of labor demand with linear adjustment costs," Labour Economics, vol. 1, no. 3-4, pp. 303-326, 1994.

[11] P. Díaz-Vázquez, D. J. Snower, and L. E. Arjona-Béjar, "Onthe-job learning, firing costs and employment," Contributions to Economic Analysis and Policy, vol. 4, no. 1, article 2, 2005.

[12] P. Díaz-Vázquez and D. J. Snower, "Employment, macroeconomic fluctuations and job security," CEPR Discussion Paper 1430, CEPR, London, UK, 1996. 
[13] P. Díaz-Vázquez and D. J. Snower, "Can insider power affect employment?” German Economic Review, vol. 4, no. 2, pp. 139150, 2003.

[14] P. Díaz-Vázquez and D. J. Snower, "On-the-job learning and the effects of insider power," Labour Economics, vol. 13, no. 3, pp. 317-341, 2006.

[15] A. Lindbeck and D. J. Snower, The Insider-Outsider Theory of Employment and Unemployment, MIT Press, Cambridge, Mass, USA, 1989.

[16] L. Ljungqvist and T. J. Sargent, "Two questions about European unemployment," Econometrica, vol. 76, no. 1, pp. 1-29, 2008.

[17] L. Nunziata, "Labour market institutions and the cyclical dynamics of employment," Labour Economics, vol. 10, no. 1, pp. 3153, 2003.

[18] Y. F. Chen, D. Snower, and G. Zoega, "Labour-market institutions and macroeconomic shocks," Labour, vol. 17, no. 2, pp. 247-270, 2003.

[19] M. Veracierto, "Firing costs and business cycle fluctuations," International Economic Review, vol. 49, no. 1, pp. 1-39, 2008.

[20] F. Zanetti, "Labor market institutions and aggregate fluctuations in a search and matching model," European Economic Review, vol. 55, no. 5, pp. 644-658, 2011. 


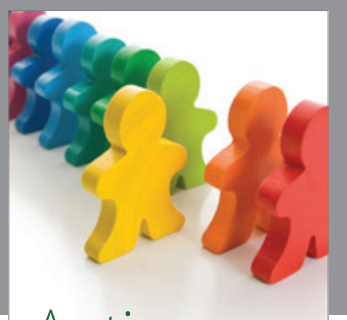

Autism

Research and Treatment
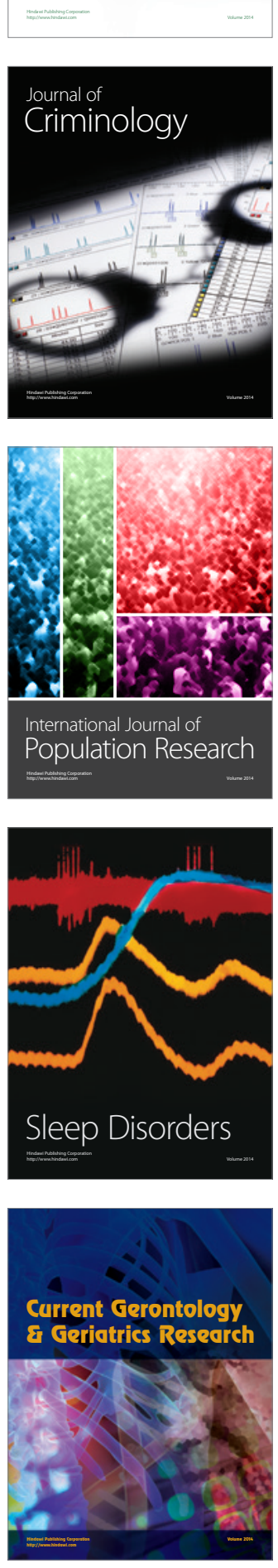
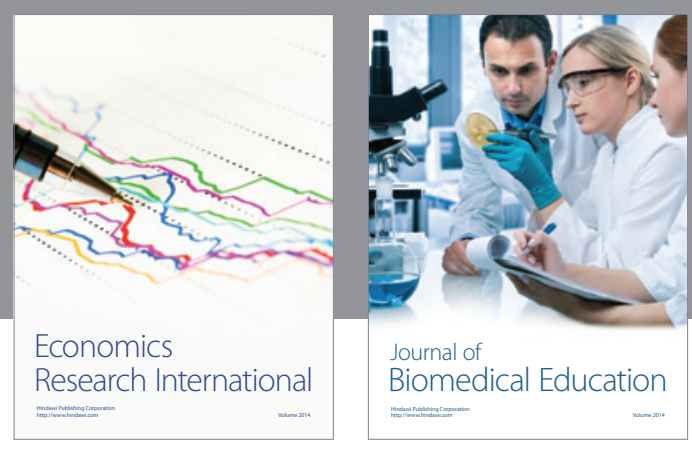

Journal of

Biomedical Education

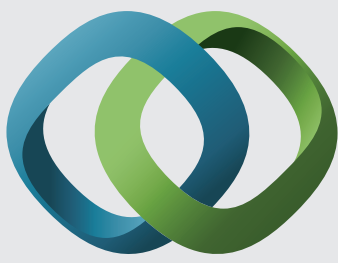

\section{Hindawi}

Submit your manuscripts at

http://www.hindawi.com
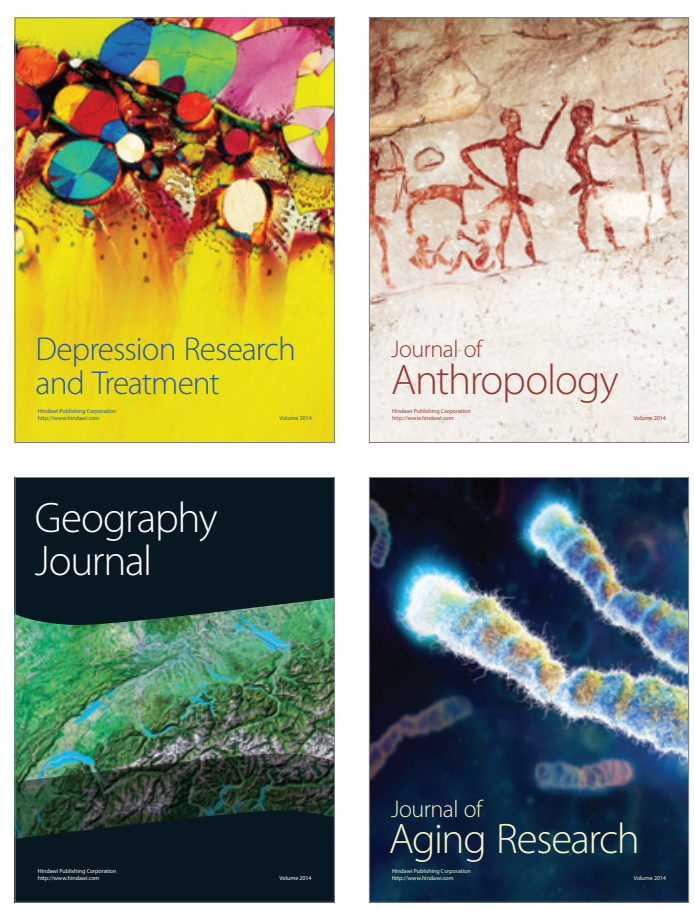

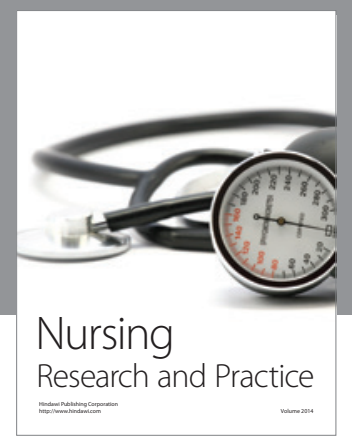

Nursing

Research and Practice

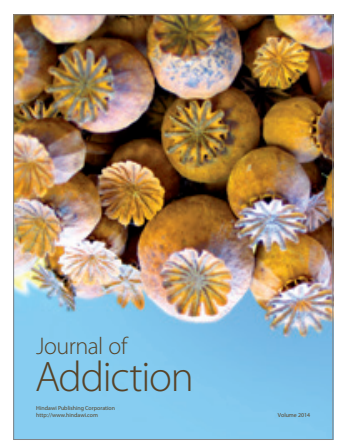

Child Development

Research

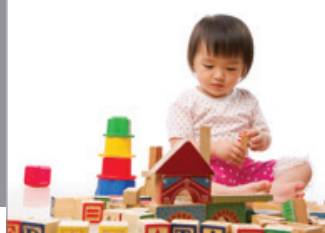

迥
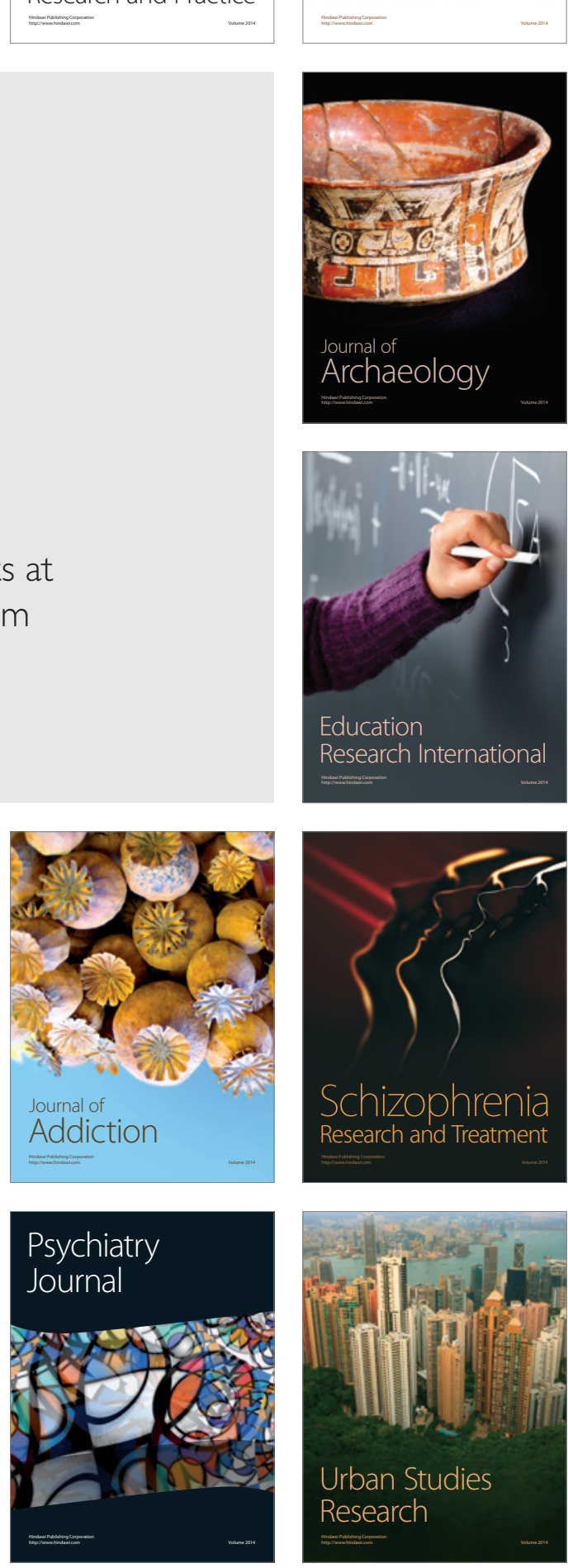